Article

\title{
Video-based health education to support insulin therapy in diabetes mellitus patients
}

\author{
Dinda M.N. Ratri, ${ }^{1,2}$ Khusnul Fitri Hamidah, ${ }^{2,3}$ Arina D. Puspitasari, ${ }^{1,2}$ Muhammad Farid ${ }^{4}$ \\ ${ }^{1}$ Department of Clinical Pharmacy, Faculty of Pharmacy, Universitas Airlangga; ${ }^{2}$ Department of Pharmacy, \\ Universitas Airlangga Teaching Hospital; ${ }^{3}$ Master of Clinical Pharmacy Student, Faculty of Pharmacy, \\ Universitas Airlangga, Surabaya; ${ }^{4}$ Faculty of Psychology, Darul Ulum University, Jombang, Indonesia
}

\begin{abstract}
Background: The improper use of insulin usually leads to some unexpected effects, hence, there is a need for right usage. Lack of knowledge and of understanding are key factors leading to the occurrence of medication errors, which could be avoided with proper education. Therefore, an appealing education alternative, such as video, is needed to improve patient's knowledge and attitudes towards insulin therapy.

Design and Methods: One-group pretest and posttest design were conducted on 100 patients with type 2 diabetes mellitus who were receiving subcutaneous insulin therapy at Internal Medicine Unit in Universitas Airlangga Teaching Hospital. The patients filled the provided questionnaires to measure their knowledge and attitudes, before and after watching the video on insulin therapy education. Then, data obtained were analysed with SPSS using Wilcoxon Signed Rank Test Method.

Results: Based on the results, there was an increase in the value of the patient's knowledge, with the value of $Z=-8.212$ and $\mathrm{P}<0.05$. Similarly, there was an increase in the patient's attitudes with the value of $\mathrm{Z}=-8.234$ and $\mathrm{P}<0.05$.

Conclusions: Insuline therapy video increases the knowledge and improves the attitude of diabetes mellitus patients towards insulin therapy.
\end{abstract}

\section{Introduction}

Diabetes mellitus is one of the most common diseases found among outpatients. ${ }^{1}$ The control of glycemic index has effect on the progression of diabetes complications, both in type 1 and type 2 diabetes. $^{2}$ In 2013 , about $6.9 \%$ of adult population in Indonesia were diagnosed with this condition of which only $21.02 \%$ of these patients received insulin therapy.,4 This insulin is a high-risk drug used in the treatment of diabetes mellitus. It is more accurately, easily and more conveniently administered with pens rather than vials and syringes. ${ }^{5,6}$ However, the independent use of an insulin pen sometimes creates issues for patients. However, this could be addressed with the right training. ${ }^{7}$ Furthermore, the long-term use of insulin, especially in elderly patients, requires adequate and continuous education. ${ }^{7}$ When not properly used, insuline could lead to complications like hyperglycemia, hypoglycemia or even death. ${ }^{8,9}$ In the United States, national surveillance data shows that 97,648 patients with cases of hypoglycemia related to the use of insulin visit the emergency rooms annually, and one-third are hospitalized. In addition, severe neurological sequelae were recorded in about $60.6 \%$ of these visits. Blood glucose levels was less than $50 \mathrm{mg} / \mathrm{dL}$ in $53.4 \%$ of these cases. ${ }^{10}$ Therefore, it is essential for health care professionals to provide detailed information with respect to instructions on injection techniques and ensure patients have adequate understanding of it. ${ }^{7}$

The different interventions to increase patient's knowledge and compliance were carried out through interviews and group discussions. In additon, technological advancement encourages health workers to handle the required tools and the condition optimally. Therefore, a method commonly used to provide information in an easily understood format is through audiovisual media. However, the effectiveness of using a video in providing information and increasing patient's understanding still has not yet been extensively studied, despite the fact that several studies shown how technology enhances learning, making audiovisual media an effective educational tool. A quantitative study also reported that video has often been used specifically for health education. ${ }^{11,12}$ The effectiveness of video as an educational media for insulin therapy on knowledge and attitude in patients with diabetes mellitus will be demonstrated in this study.

\section{Design and methods}

The study subjects were patients suffering from type 2 diabetes mellitus and receiving insulin treatment subcutaneously. they were selected during a visit to the Internal Medicine Unit at Universitas Airlangga Teaching Hospital. Those willing to participate were given the information sheets relating to details of the study. First, the participants were given questionnaire on the

Significance for public health

Information about insulin as a high alert therapy should be well known by all diabetic patients. In fact, health care professionals have reported potential misuse of insulin, particularly in outpatients. Therefore, the proper use of insulin should be well-promoted to achieve positive clinical outcomes. One potential approach to improve patient understanding on the use of insulin is through informative video. Hence, a study on the use video has been conducted to contribute promoting the proper use of insulin and preventing adverse effects of inappropriate use of insulin. 
knowledge and attitude as pre-test. Then, they watched an educational video on the screen ( \pm 13 inches) for 6 minutes, after which they filled another questionnaire as post-test. The study was conducted between August and September 2017.

The questionnaire was made up of four parts: (1) patient demographic data, (2) clinical data, (3) insulin-related knowledge, and (4) attitudes related to insulin therapy. The demographics data of the patients include name, age, educational stage, and occupational status. The clinical data include duration of suffering from type 2 diabetes mellitus, duration and frequency of insulin therapy. Then, the patient's knowledge related to insulin therapy was assessed through questions requiring true or false answers, while attitude was judged through questionnaires with the Likert scale.

The six minutes educational video was created by avoiding sophisticated medical terms so that the participants were able to fully understand the contents. This was divided into two parts, that is, specific information about type 2 diabetes mellitus and information about insulin therapy. In the first part, the participants received an explanation on its signs and symptoms, including non-pharmacological and pharmacological therapy for type 2 diabetes mellitus. Next, participants received more specific information about insulin, including the types, forms, methods of usage, rules for insulin storage, its side effects and how to handle it.

The data obtained from the questionnaires were analysed using SPSS. The demographic part was analysed as descriptive tests, the unanswered questions in the true-false part were counted as incorrect answers, while questions in the Likert scale part had a range of grades of 1 to 5 points. Then, the data analysed were classified into five categories based on theoretical value, namely very low, low, good enough, high, and very high. The difference between pre- and post-intervention scores were measured by the Wilcoxon Signed Rank Test and the significant levels were determined at a P-value of $<0.05$.

\section{Results}

A total of 100 questionnaires were completed and there were no rejected data. Before the participants filled out the questionnaire, a validity and reliability test was conducted on 30 people with the same characteristics outside the research participants group. Questionnaires with the true-false type of answer were validated by content and face validity tests, while the Pearson product moment correlation level was used to analyse the questions in the Likert scale part. Then, the validity values of each question $r>y$ table were obtained and $\mathrm{R}$ table $=0.361$. Also, the $\mathrm{R}$ count for each question in a row are as follows: $0.361 ; 0.383$; $0.572 ; 0.675 ; 0.454 ; 0.675 ; 0.136 ; 0.588 ; 0.74$. Since the R count of the seventh question was smaller than $\mathrm{R}$ table, it was considered invalid and omitted from the questionnaire. Also, the reliability test used Cronbach's alpha coefficient and the instrument obtained a reliable result with Cronbach's alpha $>0.361(\alpha=0.788)$.

The demographic data is shown in Table 1 and based on it, $58 \%$ of the participants were male and the mean age of the study population was $55.81 \pm 10.82$ years. In addition, more than half $(57 \%)$ of participants graduated from high school, while others had dissimilar education. However, $17 \%$ did not state their level of education. One third (32\%) of the participants were unemployed, especially female patients, who are housewives, while the others have different job fields such as civil servants, private employees, employers, etc.

Then, the clinical data showed the number of participants who visited at internal medicine unit in Universitas Airlangga Teaching
Hospital have been suffering from diabetes mellitus for 1-5 years $(37 \%)$, more than 5 years $(30 \%)$ and others for only 1 year $(26 \%)$. However, $7 \%$ did not remember the duration of the illness. Almost half $(41 \%)$ of participants received insulin therapy for $1-5$ years, and $38 \%$ received the therapy recently ( $<6$ months), with $62 \%$ of it as monotherapy (short, intermediate or long-acting insulin).

Based on the pre and post-intervention data analysed (Table 2), more than half of participants already have good knowledge about insulin therapy with an average score of $66.60 \pm 14.92$. However, these participants experienced a significant increase in knowledge after watching educational videos with an average score of $89.40 \pm 9.83$, the value of $\mathrm{Z}=-8.212(\mathrm{P}<0.05)$. For what concers attitude, participants with high score experienced an increase in positive attitude of $39 \%$ after intervention, with the value of $Z=-8.234$ $(\mathrm{P}<0.05)$.

\section{Results and discussion}

This research on improving knowledge and attitudes on the use of insulin injection pen through video among patients with type 2 diabetes mellitus was the first study of this kind conducted in Indonesia. A motion graphic video was used during the study, with

Table 1. Demographic data of the study population $(n=100)$

\begin{tabular}{lc} 
Category & n (\%) \\
Gender & \\
Male & $58(58)$ \\
Female & $42(42)$ \\
Age (years) & \\
$18-44$ & $15(15)$ \\
$45-64$ & $66(66)$ \\
$>65$ & $19(19)$ \\
\hline Educational stage & \\
Didn't finish primary school & $3(3)$ \\
Primary school & $5(5)$ \\
Secondary school & $57(57)$ \\
College & $18(18)$ \\
Unknown & $17(17)$ \\
Occupational status & \\
Governmental & $5(5)$ \\
Private sector & $21(21)$ \\
Entrepreneur & $10(10)$ \\
Unemployed & $32(32)$ \\
Others & $32(32)$ \\
\hline
\end{tabular}

Table 2. Pre and post-intervention after watching video on knowledge and attitude $(n=100)$.

\begin{tabular}{lcccc} 
Category & \multicolumn{2}{c}{ Knowledge } & \multicolumn{2}{c}{ Attitude } \\
& $\begin{array}{c}\text { Pre-test } \\
(\%)\end{array}$ & $\begin{array}{c}\text { Post-test } \\
(\%)\end{array}$ & $\begin{array}{c}\text { Pre-test } \\
(\%)\end{array}$ & $\begin{array}{c}\text { Post-test } \\
(\%)\end{array}$ \\
Very low & 0 & 0 & 0 & 0 \\
Low & 7 & 0 & 1 & 1 \\
\hline Good enough & 38 & 1 & 69 & 4 \\
High & 46 & 27 & 25 & 75 \\
\hline Very high & 9 & 72 & 5 & 20 \\
\hline Zvalue & $-8.212(\mathrm{p}<0.05)$ & $-8.234(\mathrm{p}<0.05)$
\end{tabular}


contents which are easily understood by participants. Overall, the study shows that the educational video is able to increase knowledge and improves the attitude towards insuline therapy among the participants, proving that the video is a good medium for providing information related to insulin therapy. The results are in line with previous research on education through audiovisual media conducted in the past. ${ }^{12}$

This study shows that $66 \%$ of the tested patients were aged 45 64 years, which aligns with the national diabetes statistic report in the United States in 2017, showing that the people newly diagnosed with diabetes mellitus were in this age range. Another study in Indonesia revealed that $25-30 \%$ of the 29.1 million diabetes mellitus patients received insulin therapy. ${ }^{13}$ However, among the 240 patients in Surabaya with diabetes mellitus, $27.9 \%$ received basal bolus therapy while $51.2 \%$ used a combination of insulin therapy and oral antidiabetic drugs. ${ }^{14}$ The potential effect of hypoglycemia of insulin therapy takes thoughtfulness in its administration, and it is important for the patients to have good knowledge on the use of this treatment. In addition, there is need for support in terms of attitude in properly administering insulin among the patients.

The patients' knowledge and attitudes were measured during this study with the aid of questionnaires, before and after watching the educational video. Before intervention, analysed data shows that more than a third of participants had good knowledge: more than half had attained high and very high category of knowledge. In terms of attitude, three-quarter participants were within the good to high category in managing and using insulin injection pen. However, few participants still had low level of knowledge and attitudes towards insulin therapy. Specifically, there was one person whose attitude did not change even post intervention. This is in line with the psychological theory which explains the ability of a person to respond differently toward the same encouragement, which is mainly due to differences in the capture of stimulus material. ${ }^{15}$ Then, after the intervention, the knowledge of the participants increased dramatically, and almost all were in the high to very high knowledge category. Identical results were obtained in the attitude aspect, in which most participants were in the high to very high category of attitude. In general, these results show that the participants already had a good knowledge and attitude towards the insulin therapy used, but got even better after watching the educational videos.

The variation of obtained data was quite wide, as many factors could affect the patient's knowledge and attitude towards the insulin therapy. A study conducted by Li et al. shows that the scores of Knowledge, Attitudes and Practice (KAP) were related to gender and occupation. Another study conducted before then also shows that female tend to have higher $\mathrm{K}$ and $\mathrm{P}$ scores but lower $\mathrm{A}$ scores, compared to the male patients. ${ }^{16}$

Additionally, educational interventions aid patient's ability in diabetes management. Several methods have been used to increase knowledge with respect to diabetes mellitus such as the use of brochures, illustrations, leaflets, and audiovisuals. A systematic review was conducted to explore the effectiveness of educational and psychosocial interventions in improving diabetes management among patients with type 1 diabetes and the results show that both interventions have a beneficial impact on diabetes management. ${ }^{17}$ Patients with low understanding of insulin injection technique showed an increasing level of $\mathrm{HbA} 1 \mathrm{C}$ and were better after being re-educated on the topic. Furthermore, a study conducted by Saengow et al. shows that educational video is a good educational technique also for long-term memory and drug adherence among patients with epilepsy disease. ${ }^{7,18}$ Hence, providing insulin-related educational contents for patients with diabetes mellitus is the beginning of an effort to encourage patients on implementing the ideal management of insulin therapy. Moreover, the patients would have a better point of view regarding the impact and goals of insulin therapy. ${ }^{15}$

However, there are some limitations in this study. It was conducted only on one treatment, observing both knowledge and attitude. There is need for further studies stretching over longer periods of time and including more frequent exposure to the educational videos.

\section{Conclusions}

In summary, this study shows a significant knowledge increase among the patients with type 2 diabetes mellitus after watching the educational video on insulin therapy. The results also indicate an improvement in patients' attitudes, which is not only in learning insulin self-injection practices but also in managing the overall condition properly.

Correspondence: Khusnul Fitri Hamidah, Department of Pharmacy, Universitas Airlangga Teaching Hospital, Kampus C Mulyorejo, Surabaya, Indonesia.

Tel.: +62315933150 - Fax. +62315935249,

E-mail: khusnul.fitri.hamidah-2018@ff.unair.ac.id.

Key words: Video-based health education; insulin therapy; diabetes mellitus.

Contributions: DR and AP designed and performed the experiments. $\mathrm{KH}$ analysed the data and wrote the manuscript. MH developed the theoretical framework. All authors provided critical feedback and helped shape the research, analysis and manuscript.

Conflict of interest: The authors declare no potential conflict of interest.

Acknowledgments: The authors would like to express our gratitude to Tri Martiana, Adi Slamet Kusumawardana and Anisah Fathiroh for their support on this project.

Clinical trials: This research has been approved by research ethics committee of Universitas Airlangga Teaching Hospital.

Conference presentation: Part of this paper was presented at the $4^{\text {th }}$ International Symposium of Public Health, October $29^{\text {th }}-31^{\text {st }}, 2019$, Griffith University, Gold Coast, Australia.

Received for publication: 6 March 2020.

Accepted for publication: 13 June 2020.

(Copyright: the Author(s), 2020

Licensee PAGEPress, Italy

Journal of Public Health Research 2020;9:1849

doi:10.4081/jphr.2020.1849

This work is licensed under a Creative Commons Attribution NonCommercial 4.0 License (CC BY-NC 4.0).

\section{References}

1. Institute for Safe Medication Practices. ISMP Guidelines for Optimizing Safe Subcutaneous Insulin Use in Adults. 
Horsham: The Institute for Safe Medication Practice (ISMP); 2017:6.

2. Gradel AKJ, Porsgaard T, Lykkesfeldt J, et al. Factors Affecting the Absorption of Subcutaneously Administered Insulin : Effect on Variability. J Diabetes Res 2018;2018:1-17.

3. Kementrian Kesehatan RI. Situasi dan Analisa Diabetes. Jakarta: Pusat Data dan Informasi Kementrian Kesehatan RI; 2014.

4. Yuniarti E, Handayani TM. Cost Analysis of Diabetes Mellitus Patients in The National Health Insurance at PKU Muhammadiyah Hospital - Comparison with INA CBGS Rates. J Kebijak Kesehat Indonesia. 2015;04:97-10.

5. Aazami S, Mozafari M, Poorabdollah H. Insulin-related outcomes (satisfaction, pain, and adherence ) among type II diabetes patients switched from syringe to insulin pen. Bali Med J 2018;7:678-81.

6. Spollett G, Edelman S V, Mehner P, et al. Improvement of Insulin Injection Technique. Sage J 2016;42:379-94.

7. Nakatani Y, Matsumura M, Monden T. Improvement of Glycemic Control by Re-education in Insulin Injection Technique in Patients with Diabetes Mellitus. Adv Ther 2013;30:897-906.

8. Bain A, Kavanagh S, Mccarthy S, et al. Assessment of Insulinrelated Knowledge among Healthcare Professionals in a Large Teaching Hospital in the United Kingdom. Pharmacy. 2019;7:1-9.

9. Lamont T, Cousins D, Hillson R, et al. Safer Administration of Insulin: Summary of A Safety Report from The National Patient Safety Agency. BMJ 2010;341:882-3.

10. Geller AI, Shehab N, Lovegrove MC, et al. National Estimates of Insulin-Related Hypoglycemia and Errors Leading to Emergency Department Visits and Hospitalizations. Jama Intern Med 2014;30333:678-86.

11. Mohammed S, Ahmed A, Taisan A, et al. The effect of A Short Animated Educational Video on Knowledge among Glaucoma Patients. Clin Opthal 2018;12:805-10.

12. Hendricks M, Nair G, Staunton C, et al. Impact of an Educational Video as A Consent Tool on Knowledge about Cure Research among Patients and Caregivers at HIV Clinics in South Africa. J Virus Erad 2018;4:103-7.

13. Davidson MB, Angeles L. Insulin Therapy: A Personal Approach. Clin Diabetes 2015;33:123-35.

14. Suprapti B, Widyasari N, Rahmadi M, et al. Review of Insulin Therapy in Type 2 Diabetes Mellitus Ambulatory Patients. Indones J Pharm 2012;28:221-31.

15. Sudirgo W, Bonang E, Musono A. Conditioning dan Proses Belajar Instrumental. Jakarta: Yayasan Penerbit Universitas Indonesia; 1973:50

16. Li Z, Jin H, Chen W, et al. Influencing Factors of Knowledge, Attitude, and Practice regarding Medical Nutrition Therapy in Patients with Diabetes: A National Cross-Sectional Study in Urban China. J Diabetes Res 2017;2017:1-10.

17. Muhammad C, Nazar J, Bojerenu MM, et al. Effectiveness of diabetes education and awareness of diabetes mellitus in combating diabetes in the United Kigdom; a literature review. J Nephropharmacology Eff 2016;5:110-5.

18. Saengow VE, Chancharoenchai P, Saartying W, et al. Epilepsy Video Animation : Impact on Knowledge and Drug Adherence in Pediatric Epilepsy Patients and Caregivers. Clin Neurol Neurosurg 2018;172:59-61. 